\title{
Effect of operational parameters, characterization and antibacterial studies of green synthesis of silver nanoparticles using Tithonia diversifolia
}

\author{
Adewumi O Dada ${ }^{\text {Corresp., }}{ }^{1}$, Adejumoke A Inyinbor ${ }^{1}$, Ebiega I Idu ${ }^{1}$, Oluwasesan M Bello ${ }^{2,3}$, Abimbola P Oluyori ${ }^{1}$ \\ , Tabitha A Adelani-Akande ${ }^{4}$, Abiodun A Okunola ${ }^{5}$, Olarewaju Dada ${ }^{6}$ \\ 1 Industrial Chemistry Programme, Department of Physical Sciences, Nanotechnology Laboratory, Landmark University, Omu Aran, Kwara State, Nigeria \\ 2 National Center for Natural Products Research, School of Pharmacy, The University of Mississippi, Mississippi, USA \\ 3 Department of Applied Chemistry, Federal University Dutsin-Ma, Dutsin-Ma, Dutsin-Ma, Katsina State, Nigeria \\ 4 Department of Biological Sciences, Microbiology Programme, Landmark University, Omu Aran, Kwara State, Nigeria \\ 5 Department of Agric \& Biosystem Engineering, Landmark University, Omu Aran, Kwara State, Nigeria \\ 6 Nigerian Stored Product Research Institute (NSPRI), Ilorin, Kwara State, Nigeria \\ Corresponding Author: Adewumi O Dada \\ Email address: dada.oluwasogo@Imu.edu.ng
}

Background:There is a growing interest on the green synthesis of silver nanoparticles using plant extract because the technique is cost effective, eco-friendly and environmentally benign. This is phasing out the use of toxic and hazardous chemical earlier reported.Tithonia diversifolia (TD) is a wide sunflower that grows widely in the western part of Nigeria with a proven medicinal benefit. However, several studies carried out have left doubting thoughts on the basic operational parameters needed for the green synthesis of AgNPs. The objective of this work was to carry out green synthesisofsilver nanoparticles usingTD extract via an eco-friendly route through optimization of various operational parameters, characterization and antimicrobial studies.

Method: Green synthesis of TD-AgNPs was done via bottom-up approach through wet chemistry technique using environmentally benignTithonia diversifoliaplant extract as both reducing and stabilizing agent. Phytochemical Screening of the TD plant extract was carried out. Experimental optimization of various operational parameters - reaction time, concentration, volume ratio and temperature was investigated. TD-AgNPs were characterized by UV-Vis spectroscopy, FTIR Spectroscopy, SEM/EDX, XRD and TEM. Antimicrobial studies against multi drug resistant microorganisms (MDRM) were studied using the agar well diffusion method.

Results:This study reveals the importance of various operational parameters in the synthesis of TDAgNPs. Excellent surface plasmon resonance peaks (SPR) were obtained at optimum experimental factors of 90 minutes reaction time under room temperature at $0.001 \mathrm{M}$ concentration with the volume ratio of 1:9 (TD extract : Ag ion solution). The synthesis was monitored using UV-Vis and maximum wavelength obtained at $430 \mathrm{~nm}$ was due to Surface Plasmon Resonance (SPR). The morphology and elemental constituents obtained by TEM, SEM and EDX results revealed a spherical shape of AgNPs with prominent peak of $\mathrm{Ag}$ at $3.0 \mathrm{keV}$ in EDX spectrum. The crystallinity nature was confirmed by XRD studies. FTIR analysis proved presence of biomolecules functioning as reducing, stabilizing and capping agents. These biomolecules were confirmed to be flavonoid, triterpenes and saponin from phytochemical screening. The antimicrobial studies of TD-AgNPs were tested against Multi-Drug Resistant Microorganisms (MDRM) -Escherichia coli, Salmonella typhi, Salmonella entericaandBacillus subtilis.

Discussion: The variation of reaction time, temperature, concentration and volume ratio played 
substantive and fundamental roles in the synthesis of TD-AgNPs. A good dispersion of small spherical size between 10 - $26 \mathrm{~nm}$ was confirmed by TEM and SEM. A dual action mechanism of anti-microbial effects was provided by TD-AgNPs which are bactericidal and membrane-disruption. Based on the antimicrobial activity, the synthesized TD-AgNPs could find good application in medicine, pharmaceutical, biotechnology and food science. 
2 Effect of Operational Parameters, Characterization and Antibacterial Studies

3 of Green synthesis of Silver nanoparticles using Tithonia diversifolia

4 Adewumi O. Dada ${ }^{*}$, Adejumoke A. Inyinbor ${ }^{1}$, Ebiega I Idu ${ }^{1}$, Oluwasesan M Bello ${ }^{2,3}$, Abimbola

5 P. Oluyori ${ }^{1}$, Tabitha A. Adelani-Akande ${ }^{4}$, Abiodun A Okunola ${ }^{5}$, Olarewaju Dada ${ }^{6}$

6

7 'Industrial Chemistry Programme, Department of Physical Chemistry, Nanotechnology

8 Laboratory, Landmark University, P.M.B.1001, Omu-Aran, Nigeria

$9{ }^{2}$ National Center for Natural Products Research, School of Pharmacy, The University of

10 Mississippi, MS 38677, USA

${ }^{3}$ Department of Applied Chemistry, Federal University Dutsin-Ma, Dutsin-Ma, Katsina State, Nigeria

${ }^{4}$ Department of Biological Sciences, Miccrobiology Programme, Landmark University, OmuAran, Nigeria

${ }^{5}$ Department of Agric\&Biosystem Enginnering, Landmark University, Omu-Aran, Nigeria

19

${ }^{6}$ Nigerian Stored Product Research Institute (NSPRI), Ilorin, Kwara State, Nigeria

21

Adewumi O. Dada

E-mail Address:

dada.oluwasogo@Imu.edu.ng 
26 Abstract

27 Background: There is a growing interest on the green synthesis of silver nanoparticles using plant extract because the technique is cost effective, eco-friendly and environmentally benign. This is phasing out the use of toxic and hazardous chemical earlier reported by different researchers. Tithonia diversifolia (TD) is a wide sunflower that grows widely in the western part of Nigeria with a proven medicinal benefit. However, several studies carried out have left doubting thoughts on the basic operational parameters needed for the green synthesis of AgNPs. The objective of this work was to carry out green synthesis of silver nanoparticles using Tithonia diversifolia extract via an eco-friendly route through optimization of various operational parameters, characterization and antimicrobial studies.

Method: Green synthesis of TD-AgNPs was done via bottom-up approach through wet chemistry technique using environmentally benign Tithonia diversifolia plant extract as both reducing and stabilizing agent. Phytochemical Screening of the TD plant extract was carried out. Experimental optimization of various operational parameters - reaction time, concentration, volume ratio and temperature was investigated. TD-AgNPs were characterized by UV-Vis spectroscopy, FTIR Spectroscopy, SEM/EDX, XRD and TEM. Antimicrobial studies against multi drug resistant microorganisms (MDRM) were studied using the agar well diffusion method.

Results: This study reveals the importance of various operational parameters in the synthesis of TD-AgNPs. Excellent surface plasmon resonance peaks (SPR) were obtained at optimum concentration with the volume ratio of 1:9 (TD extract : Ag ion solution). The synthesis was monitored using UV-Vis and maximum wavelength obtained at $430 \mathrm{~nm}$ was due to Surface Plasmon Resonance (SPR). The morphology and elemental constituents obtained by TEM, SEM and EDX results revealed a spherical shape of AgNPs with prominent peak of $\mathrm{Ag}$ at $3.0 \mathrm{keV}$ in EDX spectrum. The crystallinity nature was confirmed by XRD studies. FTIR analysis proved presence of biomolecules functioning as reducing, stabilizing and capping agents. These biomolecules were confirmed to be flavonoid, triterpenes and saponin from phytochemical screening. The antimicrobial studies of TD-AgNPs were tested against Multi-Drug Resistant Microorganisms (MDRM) - Escherichia coli, Salmonella typhi, Salmonella enterica and Bacillus subtilis.

Discussion: The variation of reaction time, temperature, concentration and volume ratio played substantive and fundamental roles in the synthesis of TD-AgNPs. A good dispersion of small spherical size between $10-26 \mathrm{~nm}$ was confirmed by TEM and SEM. A dual action mechanism 
60 of anti-microbial effects was provided by TD-AgNPs which are bactericidal and membrane61 disruption. Based on the antimicrobial activity, the synthesized TD-AgNPs could find good 62 application in medicine, pharmaceutical, biotechnology and food science.

63

64 


\section{Introduction}

In the rapidly improving field of nanotechnology, nanomaterials are on the leading front. Their special property most especially the size gives them an edge over other materials. This improves their applications in various human activities (Subba Rao et al., 2013). Silver nanoparticles among various metal nanoparticles have received significant consideration because they are effective antimicrobial agents that exhibit low toxicity; and have diverse in vitro and in vivo applications (Abou et al., 2010). Organic and inorganic nanoparticles are the two broad group classifications of nanoparticles. Silver nanoparticles have been identified as perculiar inorganic nanoparticles due to its superior properties with functional versatility leading to unending interest among researchers (Shankar et al., 2004).

In this study, green synthesis approach has been adopted because it eliminates the use and generation of hazardous substances using a bio-friendly approach that is applicable to all parts of chemistry (Sharma et al., 2008). Tithonia diversifolia (TD) plant is an ornamental shrub also known as Mexican sunflower native to Mexico and Central America from where it was introduced to Africa, Australia, Asia and South America. It widely grows in Nigeria hence its common name, Wild Sunflower. It has several applications and diverse pharmacological applications. It possesses the following pharmacological properties: anti-inflammatory, analgesic, antinociception, antimalarial, antibacterial, antitumor, antidiabetic, antidiarrheal, antihelminthic and antiviral properties (Kawlni et al., 2017). These properties of TD necessitated and gingered our research interest in utilizing it as ecofriendly and zero cost extract serving as bioreducing and stabilizing agent in the synthesis of silver nanoparticles.

There are a number of studies on the green synthesis of silver nanoparticles using different plant extracts. Syzygium aromaticum extract (Vijayaraghavan et al., 2012); Acalyphaindica leaf extract (Krishnaraj 2010); Punica granatum peel extract (Edison \& Sethuraman); banana peel extract (Ibrahim, 2015); Thevetia peruviana Juss (Oluwaniyi et al., 2015); Cavendish banana peel extract (Kokila, Ramesh \& Geetha, 2015); Oak Fruit Hull (Jaft) extract (Heydari and Rashidipour, 2015); Artocarpus heterophyllus Lam. Seed Extract (Jagtap \& Bapat, 2013) and Urtica dioica Linn. Leaves (Jyoti, Baunthiyal, Singh, 2016) were utilized in the green synthesis of silver nanoparticles. Despite all these studies carried out, experimental optimization of operational parameters and factors influencing the synthesis of silver nanoparticles have not been given a total consideration. More so, phytochemical screening of 
96

97

98

Tithonia diversifolia leaves extract, experimental optimization of operational parameters in the green synthesis of Tithonia diversifolia silver nanoparticles (TD-AgNPs), the characterization and application of TD-AgNPs have not been reported hence the need for this study. Furthermore, application of Tithonia diversifolia biosynthesized silver nanoparticles (TD-AgNPs) on MultiDrug Resistance Micro-organisms such as Escherichia coli (E.coli), Salmonella typhi, Salmonella enterica, Bacillus subtilis has not been reported. These multi-drug resistance microorganisms (MDRM) are grouped as Gram-Positive and Gram-negative bacteria. Grampositive bacteria give a positive test in Gram stain test; they have peptidoglycan layers, produce primarily exotoxins, high resistance to physical disruption, high susceptibility to anionic detergent and resistance to drying. However, Gram negative bacteria are negative to Gram stain test, they have single peptidoglycan layer with periplasmic space. They have low resistance to physical disruption, low susceptibility to anionic detergents and well as resistance to drying. Compared with Gram-positive bacteria, Gram-negative bacteria are more resistant against antibodies because of their impenetrable cell wall. They are more harmful than Gram-positive bacteria (Hoerr et al., 2012; Girish, 2014). Hence, the main reason for the choice of three Gram negative bacteria and one Gram-positive. The aims of this study are to: investigate the phytochemical screening of Tithonia diversifolia leaves extract; experimentally optimized various factors influencing the operational parameters in the green synthesis of Tithonia diversifolia silver nanoparticles (TD-AgNPs); carry out characterization and application of Tithonia diversifolia biosynthesized silver nanoparticles (TD-AgNPs) on Multi-Drug Resistance Micro-organisms.

\section{Materials and Method}

Collection of TD leaves, Preparation of Tithonia diversifolia Extract and Phytochemical Screening

Tithonia diversifolia plant (Fig. 1) was collected in Landmark University vicinity, slightly washed in order to remove the farm land soil and air-dried to avoid losing vital volatile molecules. The dried leaves were pulverized and $10 \mathrm{~g}$ of fine power of TD was added to $500 \mathrm{~mL}$ deionized water at $100{ }^{\circ} \mathrm{C}$ and left for 10 minutes. The extract was filtered using Whatman 185 $\mu \mathrm{m}$ filter paper. Phytochemical screening was carried out to identify the presence of phenols, saponins, triterpenes, flavonoids, alkaloids and steroids in the TD leaf extract. These various 
127 tests were done following the procedure in the literature (Dada et al., 2015; Senguttuvan,

128 Paulsamy \& Karthika, 2014).

\section{Synthesis of TD-AgNPs and Experimental Optimization of Operational Parameters}

130 In a typical procedure, $10 \mathrm{~mL}$ of the leaf extract was measured and poured into a clean

$131250 \mathrm{~mL}$ beaker and reacted with $90 \mathrm{~mL}$ of $1 \times 10^{-3} \mathrm{M} \mathrm{AgNO}_{3}$ at room temperature. The resulting

132 solution was stirred on the mechanical shaker at optimum operational conditions. Tithonia 133 diversifolia silver nanoparticles (TD-AgNPs) formed was separated by centrifugation at 4000 $134 \mathrm{rpm}$ for $10-15$ minutes.

135

136

137

138

139

140

141

142

143

144

145

146

147

148

149

150

151

152

153

154

155

156

\section{Experimental Optimization of operational Parameters}

Effects of four important operational parameters (experimental factors) which are concentration, reaction time, volume ratio and temperature on the formation of TD-AgNPs were investigated and the study was monitored using Biochrom Libra PCB 1500 UV-VIS spectrophotometer. Detail on the procedure has been provided in the supplementary material of this article (S1). The investigation was carried out specifically optimizing the concentrations of $\mathrm{Ag}^{+}$solution $(0.001 \mathrm{M}-0.01 \mathrm{M})$; reaction time from $5-90$ minutes; Volume ratio of plant to $\mathrm{Ag}^{+}$solution in the ratio $1: 9,2: 8,3: 7,4: 6,5: 5,6: 4,7: 3,8: 2,9: 1$ and effect of temperature.

\section{Characterization of TD-AgNPs}

All operational factors studied were monitored using Double beam Biochrom Libra PCB 1500 UV-VIS spectrophotometer. FTIR analysis was done for the determination of functional groups present in leaves extract of Tithonia diversifolia responsible for the formation of $\mathrm{Ag}$ nanoparticles that was actualized using SHIMADZU FTIR model IR8400s spectrophotometer. EDX profile coupled with the morphology determination via SEM was carried out using a TESCAN Vega TS 5136LM SEM typically at $20 \mathrm{kV}$ at a working distance of $20 \mathrm{~mm}$. TEM analysis was on Zeiss Libra $120 @ 80 \mathrm{kV}$.

\section{RESULTS}

\section{Phytochemical Screening}

Qualitative phytochemical screening analysis was done on Tithonia diversifolia (TD) leaf extract to determine the presence of some phytochemicals presence in the leaves of this medicinal plants used. The result represented in Table 1 indicates the presence of Saponins, triterpenes, flavonoid, and steroids confirming the availability of polyols which serve as the 
157 stabilizing and reducing agent. This result obtained is corroborated in the literature (Pochapski et 158 al., 2011). Detail of the phytochemical screening test are presented in the supplementary material

\section{Effects of Operational Parameters}

160 The synthesis of silver nanoparticles depends largely on some operational parameters.

161 These are factors that influence nanoparticles synthesis irrespective of the technique used. In this

162 study, evaluation of several important experimental factors, including reaction time (from 5 - 90 163 minutes, temperature, concentration of $0.001 \mathrm{M}, 0.002 \mathrm{M}, 0.004 \mathrm{M}, 0.006 \mathrm{M}, 0.008 \mathrm{M}$ and 0.01

$164 \mathrm{M}$ silver ion solution and volume ratio of 1:9, 2:8, 3:7, 4:6, 5:5, 6:4, 7:3, 8:2, 9;1 (silver ion 165 solution to TD extract) were studied. Each of these experimental factors was monitored by UV166 Vis spectroscopic measurements.

167

168

169

170

171

172

173

174

175

176

177

178

179

180

181

182

183

184

185

186

187

188

\section{Effect of Reaction time}

The reaction time and the temperature operational parameters play substantive roles in the synthesis TD-AgNPs. The effect of reaction time was investigated by steady monitoring the reaction of the plant extract and $\mathrm{AgNO}_{3}$ for 5, 10, 20, 30, 45, 60 and 90 minutes at room temperature. The moment TD extract reacts with the solution of $\mathrm{AgNO}_{3}$, a colour change was observed from green to brown within 10 minutes of reaction. The colour intensified with increase in time (Balavandy et al., 2014). UV-Vis measurements were taken at various time intervals as shown in Fig. 2A. It can be inferred that between zero and 10 minutes, the SPR band is broadened because of the slow conversion of silver ion $\left(\mathrm{Ag}^{+}\right)$to zerovalent silver $\left(\mathrm{Ag}^{0}\right)$ nanoparticles. Excellent surface plasmon resonance band was observed as the reaction time increases because large amount of $\mathrm{Ag}^{+}$has been converted to $\mathrm{Ag}^{0}$. The $\mathrm{UV}-\mathrm{V}$ is spectra measured showed the absorption of TD-AgNPs synthesized nanostructures and best SPR peak was observed within $430 \mathrm{~nm}$ at 90 minutes. Reports from the literature have shown that when the colour is stable and a narrow shape of the SPR has been achieved, optimum time is reached. Supporting this observation is the outcome of the study by Mohamed et al. (2014) and Anandalakshmi et al. (2016) where a rapid synthesis was obtained at lower time and this was their optimum time. The UV-Vis spectra measured showed the absorption of TD-AgNPs synthesized nanostructures and best SPR peak was observed within $430 \mathrm{~nm}$ at 90 minutes. Further investigation of other operational parameters was carried out at 90 minutes which is the optimum time obtained.

\section{Effect of Temperature}


A further study on the effect of temperature on the synthesis of AgNP was carried out at

190

191

192

193

194

195

196

197

198

199

200

201

202

203

204

205

206

207

208

209

210

211

212

213

214

215

216

217

218

219 $45^{\circ} \mathrm{C}$ and $55^{\circ} \mathrm{C}$ as shown in Fig. 2(B-C). From the literature, it has been reported that increase in temperature leads to increase in the intensity of the surface plasmon resonance band as a result of bathochromic shift resulting in a decrease in the mean diameter of silver nanoparticle (Bindhu \& Umadevi, 2014). This however may not connote the optimum temperature where excellent SPR band maybe obtained. In this study, excellent representation was obtained at room temperature because the biomolecules from the TD extract effectively reduced and stabilized silver nanoparticles at ambient temperature. Stable TD-AgNPs was formed at room temperature thus justifying the green synthetic route

\section{Effect of Concentration}

Depicted in Fig. 2D is the UV-Vis spectra of effect of concentration on the synthesis of TD-AgNPs. This operational parameter was monitored at various concentrations of silver ion solution and at optimum conditions. The investigation was carried out on the following concentration: $0.001 \mathrm{M}, 0.002 \mathrm{M}, 0.004 \mathrm{M}, 0.006 \mathrm{M}, 0.008 \mathrm{M}$ and $0.01 \mathrm{M}$. The intensity increases as the concentration of $\mathrm{Ag}^{+}$increases with the Surface Plasmon Resonance peak for all the different concentrations. A distinctive SPR peak at $430 \mathrm{~nm}$ was obtained at $0.001 \mathrm{M} \mathrm{Ag}^{+}$ concentration. Varying the concentration of $\mathrm{Ag}^{+}$solution affects the size and shape of the silver nanoparticles (Filippo et al., 2010).

\section{Effect of Volume Ratio}

Portrayed in Fig. 2E is the surface plasmon peaks on the investigation of effect of volume ratio. This was studied varying the volume ratio of the leaf extract to $0.001 \mathrm{M} \mathrm{Ag}^{+}$solution in the ratio $1: 9,2: 8,3: 7,4: 6,5: 5,6: 4,7: 3,8: 2,9: 1$. The absorption peaks were broader and irregular at higher volume of extract indicating a slow reduction of $\mathrm{Ag}^{+}$to $\mathrm{Ag}^{0}$ and presence of silver nanoparticles with broader size distribution (Peng, Yang \& Xiong, 2013; Oluwaniyi et al., 2015). As the volume of $\mathrm{Ag}^{+}$solution increased, the absorption peak became sharper with excellent enhancement in the absorption band intensity at $430 \mathrm{~nm}$. The SPR peaks in UV-Vis spectra showed best representation in ratio 1:9 (TD extract: $\mathrm{Ag}^{+}$solution). This indicates that TD extract stabilizes and bioreduces silver ion at ratio 1:9 giving $430 \mathrm{~nm}$ as a result of surface plasmon resonance. Thus further study was carried out using the optimum volume ratio 


\section{CHARACTERIZATION}

222

223

224

225

226

227

228

229

230

231

232

233

234

235

236

237

238

239

240

241

242

243

244

245

246

247

248

\section{UV-Vis Spectroscopic study}

The most imperative characterization technique for studying the synthesis of silver nanoparticle is the UV-Vis spectroscopy. In this study, the colour change was observed from the absorption in the visible range. The absorption of light occurs in the visible region of the electromagnetic spectrum where atoms and molecules undergo electronic transition of $\pi-\pi^{*}, n-\pi^{*}, \sigma-\sigma^{*}$, and $n-\sigma^{*}$. Absorption of energy in the form of ultraviolet or visible light is by molecules containing $\pi$ electrons or non-bonding electrons (n-electrons) to excite these electrons to higher anti-bonding molecular orbitals. The length of wave depends on the excitation of the electrons, the more easily excited the electrons, the longer the wavelength of light it can absorb (Dada et al., 2018).

Oscillation of electron at the surface of silver nanoparticles brought about the surface plasmon resonance (SPR) resulting from the change of colour from green to yellow and finally brown. UV-Vis measurements were taken to study the formation of silver nanostructures in the reaction of Tithonia diversifolia with silver nitrate $\left(\mathrm{AgNO}_{3}\right)$ and this is presented in Fig. 3(a)

\section{FTIR Spectroscopic Study}

The result of the phytochemical screening was corroborated by the FTIR spectroscopic study. Presented in Fig. 3(b) is the FTIR result of TD-AgNps identifying the biomolecules that were bound specifically on the TD-AgNPs. It is obvious that the biomolecules are responsible for the reduction of $\mathrm{Ag}^{+}$to $\mathrm{Ag}^{0}$. This was well elucidated in the Discussion Section of this article.

\section{SEM, EDX, TEM and XRD Studies}

Important characterization signatures were provided by SEM, EDX, TEM and XRD results which are very imperative to this study.

SEM identifies the surface characteristics, morphology and the distribution of the TDAgNPs depicted on the SEM micrograph (Fig. 3c) (Dada, Adekola \& Odebunmi, 2017 a).

Energy-dispersive X-ray spectroscopy (EDX) gives information on the surface atomic distribution and the chemical elemental composition of metallic nanoparticles. Fig. 3d depicts the 
249 EDX of TD-AgNPs which reveals a very strong signal in the silver region at $3 \mathrm{keV}$ and confirms 250 the formation of AgNPs.

251 The Transmission electron microscopy (TEM) is also one of the valuable tools for 252 characterization of metallic nanoparticles because it unravels the size, shape and morphology. 253 Depicted in Fig. 3(e) is the TEM image of TD-AgNPs showing a characteristic spherical shape 254 of Ag nanoparticles.

255 X-ray diffraction (XRD) result revealed the crystalline structure of TD-AgNPs as shown 256 in Fig. 3(f). Four distinct characteristic peaks indicated at angles $38^{\circ}, 44^{\circ}, 65^{\circ}$ and $78^{\circ}$.

\section{ANTIMICROBIAL STUDIES}

259

260

261

262

263

264

265

266

267

268

269

270

271

272

273

274

275

276

277

278

279

The antimicrobial study was carried out using agar well diffusion method. $0.2 \mathrm{~mL}$ of the TDAgNPs solution, TD leaf extracts, the positive control (Ciproflaxcin) and negative control (sterile water) were introduced into the well accordingly. The plates were left to diffuse for 1 hour before placing them in an incubator at $37^{\circ} \mathrm{C}$ for 24 hours. After the incubation period, the mean diameters of the zones of inhibition around the wells were recorded and presented in Table S1. The results of the antimicrobial studies are presented in Fig. S1, Fig.4 and Table S2. Shown in Fig S1 are the plates of the various zones of inhibitions for different bacteria investigated. The measurement of the zone of inhibition is presented in Table S1. However, Fig. 4 showed the bar chart representation of the antimicrobial activity of synthesized silver nanoparticles (TDAgNPs), TD Extract, Positive Control and Negative Control against Escherichia coli, Salmonella typhirium, Salmonella enterica and Bacillus subtilis. The result indicated TD-AgNPs is very effective against these multi-drug resistance organisms while both the TD leaves extract and the negative control sample was not active at all.

\section{Discussion}

The aims of this study were successfully achieved. Phytochemical screening revealed the presence of functional biomolecules responsible for the bioreduction of $\mathrm{Ag}^{+}$to $\mathrm{Ag}^{0}$. This study has examined four major operational parameters as revealed in Figs 2(A-E). These are imperative to the synthesis of silver nanoparticles. The operational parameters were monitored using the UV-Vis spectrophotometer. The study established that excellent SPR peaks formed at $430 \mathrm{~nm}$ were obtained at reaction time of 90 minutes (Fig. 2A), under optimum experimental 
280 conditions. Effect of temperature at $45^{\circ} \mathrm{C}$ (Fig. 2B) and $55^{\circ} \mathrm{C}$ (Fig. 2C) revealed the dependence

281 of the TD-AgNPs synthesis on temperature. However, the room temperature synthesis is greener 282 than the heated syntheses, which is a further advantage. The effect of concentration affects the 283 size of the TD-AgNPs. At higher concentrations (0.004 M; $0.006 \mathrm{M} ; 0.008 \mathrm{M}$ and $0.01 \mathrm{M})$, there 284 was change in the intensity as a result of bathochromic shift leading to broad band, lower size, 285 dispersion and higher aggregation. However, at lower $\mathrm{Ag}^{+}$concentrations $(0.001 \mathrm{M}$ and 0.002 $286 \mathrm{M}$ ), higher intensity, better absorbance and narrower bands were observed as seen in Fig 2D. The 287 effect of concentration resultantly influences its particle size. SPR band maximum intensity and 288 band width are influenced by particle shape, dielectric constant of the medium and temperature 289 (Narayanan \& Sakthivel, 2011). This enhanced a good shape and size control. This finding is 290 supported by the report of Kokila et al., (2015). Best surface plasmon resonance was obtained at 291 292 spherical characteristics shape confirmed by TEM and SEM. Best volume ratio of 1:9 (TD extract : $\mathrm{Ag}^{+}$solution) was observed suitable for better and stable TD-AgNPs formation. TD-AgNPs were characterized by UV-Vis (Fig. 3a), FTIR (Fig. 3b), SEM (Fig 3c), EDX (Fig. 3d) and XRD (Fig. 3e). Fig. 3(a) revealed that the maximum absorption was observed at $430 \mathrm{~nm}$ which was due to the AgNPs surface plasmon resonance (SPR) band. The surface plasmon resonance is as a result of the free electron arising from the conduction and valence bands lying close to each other in metal nanoparticles (Anandalakshmi et al., 2016; Dada et al., 2018). This SPR peak gives a convenient spectroscopic signature for the formation of silver nanoparticle (AgNPs) and a clue on the spherical shape of silver nanoparticle. This corroborates with the TEM measurement (Pandey, Goswami \& Nanda, 2012; Van et al., 2012).

The FTIR spectrum was recorded in the region of $4000-500 \mathrm{~cm}^{-1}$ region (Fig 3b) signifying the absorbance bands centered as follows: $3321 \mathrm{~cm}^{-1}$ is assigned to polyols; $2240 \mathrm{~cm}^{-1}$ corresponds to $\mathrm{C}-\mathrm{H}$ stretching vibration; peak at $1692 \mathrm{~cm}^{-1}$ to $\mathrm{N}-\mathrm{H}$ vibration stretching; peak at $1615 \mathrm{~cm}^{-1}$ corresponds to $-\mathrm{C}=\mathrm{C}-$ of aromatic ring; $1555 \mathrm{~cm}^{-1}$ : $\mathrm{C}-\mathrm{N}$ stretching of amines; 1194 $\mathrm{cm}^{-1}$ for $\mathrm{C}-\mathrm{N}$ stretching of aromatic amine group and the bands observed at $1009 \mathrm{~cm}^{-1}$ corresponds to $\mathrm{C}-\mathrm{H}$ stretching of polysaccharides; $665 \mathrm{~cm}^{-1}: \mathrm{N}-\mathrm{H}$ wag of amines. FTIR result obtained confirmed the phytochemical screening result of some biomolecules. It implies that the biomolecules functioned as reducing, capping and stabilizing agents. Analysis of FTIR result indicates that the silver nanoparticles were surrounded by terpenoids, alcohols, lactone and 
311 carbonyl group from amine serving as strong binding site for AgNPs (Dubey et al., 2010; Edison

312 et al., 2013; Tran et al.2013; Dada, Adekola \& Odebunmi, 2017b).

313 It is evident from the SEM micrograph (Fig. 3c) that the morphology of TD-AgNP is 314 spherical and this is in good agreement with the shape of Surface Plasmon Resonance (SPR) 315 band in the UV-Vis spectrum (Benn \& Westerhoff, 2008; Singh, Saikia and Buragohain, 2013; 316 Dada, Adekola \& Odebunmi, 2017c).

317 Fig. 3(d) depicts the EDX spectrum of TD-AgNPs which reveals a very strong signal in 318 the silver region and confirms the formation of AgNPs. Metallic silver nanocrystals have a 319 characteristic peak at $3 \mathrm{keV}$ due to SPR. The other peaks observed were found to be other 320 elemental constituents in the plants and the gold $\mathrm{Au}$ ) seen on the spectrum resulted from the 321 preparation of the samples for the EDX characterization (Bankura et al., 2012; Seo et al., 2012; 322 Dada, Adekola \& Odebunmi, 2015).

323 The characteristic spherical shape of TD-AgNPs is further confirmed from the TEM image presented in Fig. 3(e). A good dispersion of small spherical size between $10-26 \mathrm{~nm}$ was observed (Babu and Gurumallesh, 2011; Prathna et al., 2011). The antimicrobial activity is a function of the size of the nanoparticle (Tippayawat et al., 2016)

Depicted in Fig. 3(f) is the X-ray diffraction result which confirmed the crystalline structure of TD-AgNPs. The four intense peaks appearing around $38^{\circ}, 44^{\circ}, 65^{\circ}$ and $78^{\circ}$ fits in perfectly to the (111), (200), (220) and (311) lattice planes. This maybe indexed as the band for face centered cubic structures of silver. This XRD result confirmed the crystallinity nature of silver nanoparticles synthesized using Tithonia difersifilia extract (Bar et al., 2009; Wen et al., 332 2012).

The in vitro antimicrobial studies on MDRM were carried out using leaf extract of Tithonia diversifolia, TD-AgNPs synthesized, sterile water (negative control) and Ciproflaxcin (Positive control and for comparison of the effectiveness of synthesized TD-AgNPs ). Details on the antimicrobial procedure are stated in the supplementary material of this article (S2-S8) and Table S2. Fig. 4 shows the result of the antimicrobial activity indicating the growth inhibition of the TD-AgNPs and the positive control. The results showed that the leaf extracts of Tithonia diversifolia and the negative control (sterile water) had no significant activity or effect on the microorganisms. This finding is supported by the study carried out by Tran et al. (2013). However the significant inhibitory antimicrobial activity was shown by synthesized silver 
342 nanoparticles (TD-AgNPs) with inhibition zones varying from $10 \mathrm{~mm}$ to $15 \mathrm{~mm}$ (Table S1).

343 These results were further analyzed statistically to compare the inhibitory effect of TD-AgNPS

344 to the positive control (Ciproflaxcin) used as shown in Fig. 4. More inhibitory activity of the

345 synthesized nanoparticles occurred on Bacillus subtilis with inhibition zone of $15 \pm 0.34 \mathrm{~mm}$ than

346 the rest of the microorganisms as observed. It was also observed in relative terms versus the

347 positive control, the best inhibition seems to be $S$. enterica. A dual action mechanism of anti-

348 microbial effects was provided by TD-AgNPs which are bactericidal and membrane-disruption.

349 This is corroborated by the report of Jain et al. (2009); Sharma, Yngard \& Lin, (2009).

350

351 CONCLUSION

352 The green synthesis of silver nanoparticle using eco-friendly and environmentally benign

353 Tithonia diversifolia plant extract was successfully carried out. This study shows that the

354 synthesis of Tithonia diversifolia silver nanoparticles (TD-AgNPs) depends on various

355 experimental operational parameters. It can be concluded that optimum concentration of 0.001

$356 \mathrm{M} \mathrm{Ag}^{+}$solution, reaction time of 90 minutes, ambient temperature for stability of biomolecules,

357 and volume ratio of 1:9 favours the optimum yield of TD-AgNPs. TD-AgNPs were

358 characterized by different spectroscopic and microscopic techniques. The presence of

359 biomolecules (flavonoids and terpenoids) in TD extract observed from the phytochemical

360 screening was confirmed by FTIR spectroscopic study. These biomolecules serve as the

361 reducing, stabilizing and capping agents changing $\mathrm{Ag}^{+}$to $\mathrm{Ag}^{0}$. Surface plasmon peak was

362 observed at $430 \mathrm{~nm}$ by UV-Vis spectroscopic measurement. Spherical shape and $10-26 \mathrm{~nm}$ size

363 of TD-AgNPs were determined by SEM and TEM. Elemental composition of TD-AgNPs with

364 an intense peak of $\mathrm{Ag}$ at $3.0 \mathrm{keV}$ was determined by EDX and the crystallinity nature of $\mathrm{Ag}$

365 nanoparticles by XRD. Antimicrobial studies carried out against multidrug resistance

366 microorganism showed the efficacy and efficiency of TD-AgNPs as observed in the inhibitory

367 function. It is obvious that TD-AgNPs showed activity against Gram Positive and Gram

368 Negative micro-organism. It can therefore be concluded that TD-AgNPs would find application

369 in Medicine, Pharmacology and Food Science.

370

371 Acknowledgement 
372 The authors appreciate the Management of Landmark University for providing research facilities

373 and enabling environment for result oriented studies for breaking new grounds.

374

375

376

377

378

379

380

381

382

383

384

385

386

387

388

389

390

391

392

393

394

395

396

397

398

399

400

401

402

403

404

405

406

407

408

409

410

\section{References}

Abou El-Nour KMM, Eftaiha A, Al-Warthan A, Ammar R. 2010. Synthesis and applications of silver nanoparticles. Arab Journal Chemistry 3: 135-140.

Anandalakshmi K, Venug obal J, Ramasamy V (2016). Characterization of silver nanoparticles by green synthesis method using Pedalium murex leaf extract and their antibacterial activity. Appl Nanosci, 6:399-408. DOI 10.1007/s13204-015-0449-z

Babu SA, Prabu HG. (2011). Synthesis of AgNPs using the extract of Calotropis procera flower at room temperature. Materials Letters, 65 (11): 1675-1677.

Balavandy SK, Shameli K, DRBA, Abidin ZZ. (2014). Stirring time effect of silver nanoparticles prepared in glutathione mediated by green method. Chemistry Central Journal, 8 (11), 1 - 10. doi:10.1186/1752-153X-8-11.

Bankura KP, Maity D, Mollick MMR, Mondal D, Bhowmick B, Bain MK, Chakraborty A, Sarkar J,Acharya K,Chattopadhyay D. 2012. Synthesis,characterization and antimicrobial activity of dextran stabilized silver nanoparticles in aqueous medium. Carbohydrate Polymers 89: 1159- 1165

Bar H, Bhui DK, Sahoo GP, Sarkar P, Pyne S, Misra A. 2009. Green synthesis of silver nanoparticles using seed extract of Jatropha curcas. Colloids and Surfaces A: Physicochemical and Engineering Aspects 348: 212-216

Benn TM, Westerhoff P. 2008. Nanoparticle Silver Released into Water from Commercially Available Sock Fabrics. Environmental Science and Technology, 42: 4133-4139

Bindhu MR, Umadevi M (2014). Silver and gold nanoparticles for sensor and antibacterial applications. Spectrochim Acta Part A Mol Biomol Spectrosc 128:37-45

Dada AO, Adekola FA, Adeyemi OS, Bello MO, Adetunji CO \& Awakan OJ (2018). Silver Nanoparticles - fabrication, characterization and applications. Chapter 9, pg $165-184$.

Doi.org/10.5772/intechopen.76947

Dada AO, Adekola FA, Odebunmi EO. 2017 ${ }^{\text {a }}$ Liquid Phase Scavenging of Cd (II) and Cu (II) ions onto novel nanoscale zerovalent manganese (nZVMn): Equilibrium, Kinetic and Thermodynamic Studies. Environmental Nanotechnology, Monitoring \& Management: 8, 63-72 : //dx.doi.org/10.1016/j.enmm.2017.05.001 
411 Dada AO, Adekola FA, Odebunmi EO .2017 . Kinetics, Mechanism, Isotherm and

412 Thermodynamic Studies of Liquid Phase Adsorption of $\mathrm{Pb}^{2+}$ onto Wood Activated Carbon

413 Supported Zerovalent Iron (WAC-ZVI) Nanocomposite. Cogent Chemistry Journal. 3: 1351653,

414 pg 1-20. DOI: http://doi.org/10.1080/23312009.2017.1351653

415

416 Dada AO, Adekola FA, Odebunmi EO .2017c. Novel zerovalent manganese for removal of 417 copper ions: Synthesis, Characterization and Adsorption studies. Applied water Science, 7:1409-

418 1427 Doi: 10.1007/s13201-015-0360-5

419

420

Dada AO, Adekola FA, Odebunmi EO. 2015. Kinetics and equilibrium models for Sorption of

421 $\mathrm{Cu}$ (II) onto a Novel Manganese Nano-adsorbent. Journal of Dispersion Science and Technology,

422 37(1), 119 - 133. DOI: 10.1080/01932691.2015.103461

423

424

425

426

427

428

429

430

431

432

433

434

435

436

437

438

439

440

441

442

443

444

445

446

447

Dubey SP, Lahtinen M, Sillanpää M. 2010. Green synthesis and characterizations of silver and gold nanoparticles using leaf extract of Rosa rugose. Colloids and Surfaces A: Physicochem. Eng. Aspects 364, 34-41

Edison TJ, Sethuraman MG. 2013. Biogenic robust synthesis of silver nanoparticles using Punica granatum peel and its application as a green catalyst for the reduction of an anthropogenic pollutant 4-nitrophenol. Spectrochimica Acta Part A: Molecular and Biomolecular Spectroscopy, 104: $262-264$

Filippo E, Serra A, Buccolieri A, Manno D. 2010. Green synthesis of silver nanoparticles with sucrose and maltose: Morphological and structural characterization. Journal of Non-Crystalline Solids, 356: 344-350

Girish R (2014). Gram-positive and gram-negative bacterial toxins in sepsis: A brief review. Virulence, 5:1, 213-218

Heydari R and Rashidipour M. 2015. Green Synthesis of Silver Nanoparticles Using Extract of Oak Fruit Hull (Jaft): Synthesis and In Vitro Cytotoxic Effect on MCF-7 Cells. International Journal of Breast Cancer Volume 2015, Article ID 846743, 6 pages http://dx.doi.org/10.1155/2015/846743

Hoerr V, Zbytnuik L, Leger C, Tam PCP, Kubes P, and Vogel HJ (2012). Gram-negative and Gram-Positive Bacterial Infections Give Rise to a Different Metabolic Response in a Mouse Model. Journal of Proteome Research, 11 (6), 3231-3245

Ibrahim HMM. 2015. Green synthesis and characterization of silver nanoparticles using banana peel extract and their antimicrobial activity against representative microorganisms. Journal of Radiation Research and Applied Sciences 8: 265 - 275 
448

449

450

451

452

453

454

455

456

457

458

459

460

461

462

463

464

465

466

467

468

469

470

471

472

473

474

475

476

477

478

479

480

481

482

483

Jagtap UB, Bapat VA. 2013. Green Synthesis of Silver Nanoparticles Using Artocarpus heterophyllus Lam. Seed Extract and Its Antibacterial Activity. Industrial Crops and Products, 46: 132-137.http://dx.doi.org/10.1016/j.indcrop.2013.01.019

Jain D, Daima HK, Kachhwaha S, Kothari SL. 2009. Synthesis of Plant-Mediated Silver Nanoparticles using Papaya Fruit Extract and Evaluation of Their Anti-Microbial Activities. Digest Journal of Nanomaterials and Biostructures. 4(3): 557 - 563

Jyoti K, Baunthiyal M, Singh A. 2016. Characterization of silver nanoparticles synthesized using Urtica dioica Linn. leaves and their synergistic effects with antibiotics. Journal of Radiation Research and Applied Sciences. 9: 217-227

Kawlni L, Bora M., Upadhyay SN, Hazra J. (2017). Pharmacological Profile of Tithonia diversifolia (Hemsl.) A. Gray: A Comprehensive Review. J Drug Res Ayurvedic Sci, 2(3): 183 187.

Kokila T, Ramesh PS, Geetha D. 2015. Biosynthesis of silver nanoparticles from Cavendish banana peel extract and its antibacterial and free radical scavenging assay: a novel biological approach. Applied Nanoscience5: 911-920

Krishnaraj C, Jagan EG, Rajasekar S, Selvakumar P, Kalaichelvan PT. 2010. Synthesis of silver nanoparticles using Acalyphaindica leaf extracts and its antibacterial activity against water borne pathogens. Colloids Surf B Biointer 76: 50-56.

Mohamed NH, Ismail MA, Abdel-Mageed WM, Shoreit AAM (2014). A ntimicrobial activity of latex silver nanoparticles using Calotropis procera. Asian Pac J Trop Biomed, 4(11): 876-883

Narayanan KB, Sakthivel N (2011). Extracellular synthesis of silver nanoparticles using the leaf extract of Coleus amboinicus Lour. Materials Research Bulletin 46,1708-1713

Oluwaniyi OO, Adegoke HI, Adesuji ET, Alabi AB, Bodede SO, Labulo AH, and Oseghale CO. 2015. Biosynthesis of silver nanoparticles using aqueous leaf extract of Thevetia peruviana Juss and its antimicrobial activities. Applied Nanoscience DOI 10.1007/s13204-015-0505-8

Pandey S, Goswami GK, Nanda KK. 2012. Green synthesis of biopolymer-silver nanoparticle nanocomposite: An optical sensor for ammonia detection. International Journal of Biological Macromolecules. 2012; 51: 583- 589

Peng H, Yang A, Xiong J. 2013. Green, microwave-assisted synthesis of silver nanoparticles using bamboo hemicelluloses and glucose in an aqueous medium. Carbohydrate Polymers 91, $348-55$

Prathna TC, Chandrasekaran N, Raichur AM, Mukherjee A. 2011. Kinetic evolution studies of silver nanoparticles in a bio-based green synthesis process Colloids and Surfaces A: 
484

485

486

487

488

489

490

491

492

493

494

495

496

497

498

499

500

501

502

503

504

505

506

507

508

509

510

511

512

513

514

515

516

517

518

519

520

521

Physicochem. Eng. Aspects; 377:212-216.

Senguttuvan J, Paulsamy S, Karthika K. 2014. Phytochemical analysis and evaluation of leaf and root parts of the medicinal herb, Hypochaeris radicata L. for in vitro antioxidant activities. Asian Pac J Trop Biomed; 4(Suppl 1): S359 - S367

Seo YS, Lee GH, Lee SG, Jung SY, Lim JO, Choi JH. 2012. Alginate-based composite sponge containing silver nanoparticles synthesized in situ. Carbohydrate Polymers 90: 109115

Singh S, Saikia JP, Buragohain AK. 2013. A novel 'green' synthesis of colloidal silver nanoparticles (SNP) using Dillenia indica fruit extract. Colloids and Surfaces B: Biointerfaces $102,83-85$

Sharma KV, Yngard RA, Lin Y. 2009. Silver nanoparticles: Green synthesis and their antimicrobial activities. Advances in Colloid and Interface Science 145: 83-96

Shankar SS, Rai A, Ahmad A, Sastry MJ 2004. Rapid synthesis of Au, Ag and bimetallic Au shell nanoparticles using Neem. Journal of Colloid and Interface Science, 275: 496-502.

Subba Rao Y, Kotakadi VS, Prasad TNVKV, Reddy AV, Sai Gopal DVR. 2013, Green synthesis and spectral characterization of silver nanoparticles from Lakshmi tulasi (Ocimum sanctum) leaf extract, Spectrochimica Acta Part A: Molecular and Biomolecular Spectroscopy, Volume 103: Page 156-159

Tippayawat P, Phromviyo N, Boueroy P and Chompoosor A. 2016. Green synthesis of silver nanoparticles in aloe vera plant extract prepared by a hydrothermal method and their synergistic antibacterial activity. PeerJ 4:e2589; DOI10.7717/peerj.2589

Tran TTT, Vu, THT, Hanh Thi Nguyen, T.H. 2013. Biosynthesis of silver nanoparticles using Tithonia diversifolia leaf extract and their antimicrobial activity. Mater Lett (2013), http ://dx.doi.org/10.1016/j.matlet.2013.0 4.021

Van Dong P, Ha CH, Binh LT, Kasbohm J (2012). Chemical synthesis and antibacterial activity of novel-shaped silver nanoparticles. International Nano Letters, 2 (9): 1- 9

Vijayaraghavan K, Kamala Nalini SP, Prakash NU, Madhankumar D. (2012), Biomimetic synthesis of silver nanoparticles by aqueous extract of Syzygium aromaticum, Materials Letters, 75: Page 33-35

Wen C, Shao M, Zhuo S, Lin Z, Kang Z (2012). Silver/graphe ne nanocomposite: Thermal decomposition prep catalytic performance. Materials Chemistry and Physics. 2012; 135: 780 785 


\section{Figure 1}

\section{A typical Tithonia diversifolia plant}

Source credit: Ebiega I Idu.

*Note: Auto Gamma Correction was used for the image. This only affects the reviewing manuscript. See original source image if needed for review.

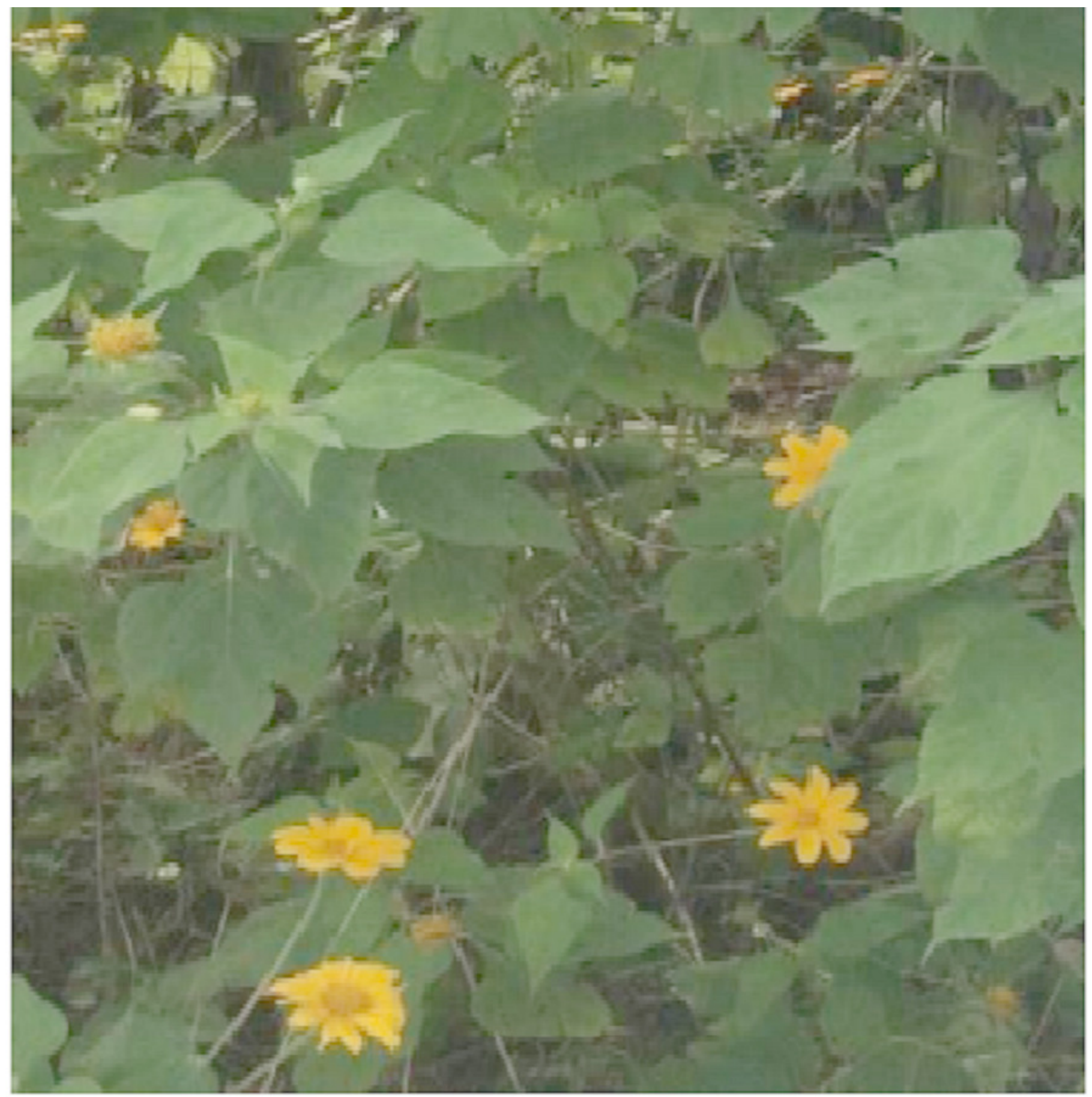


Figure 2 (on next page)

Effects of operational parameters (Resubmission)

UV-Vis absorption spectra for Experimental Optimization on: (A) Effect of Contact time (B) Effect of temperature at $45^{\circ} \mathrm{C}$ (C) Effect of temperature at $55^{\circ} \mathrm{C}$ (D) Effect of Concentration (E) Effect of Volume ratio 

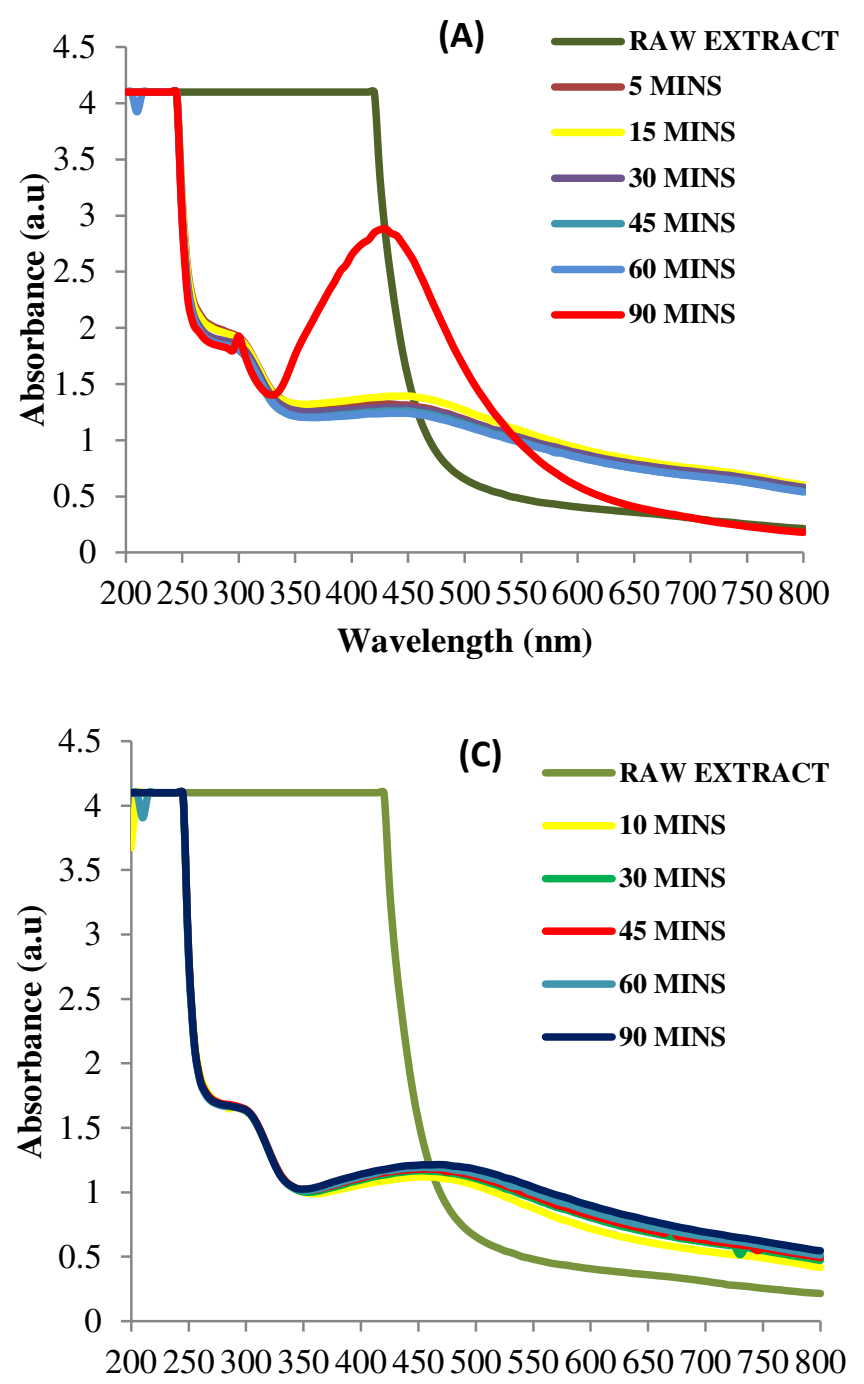

Wavelength (nm)

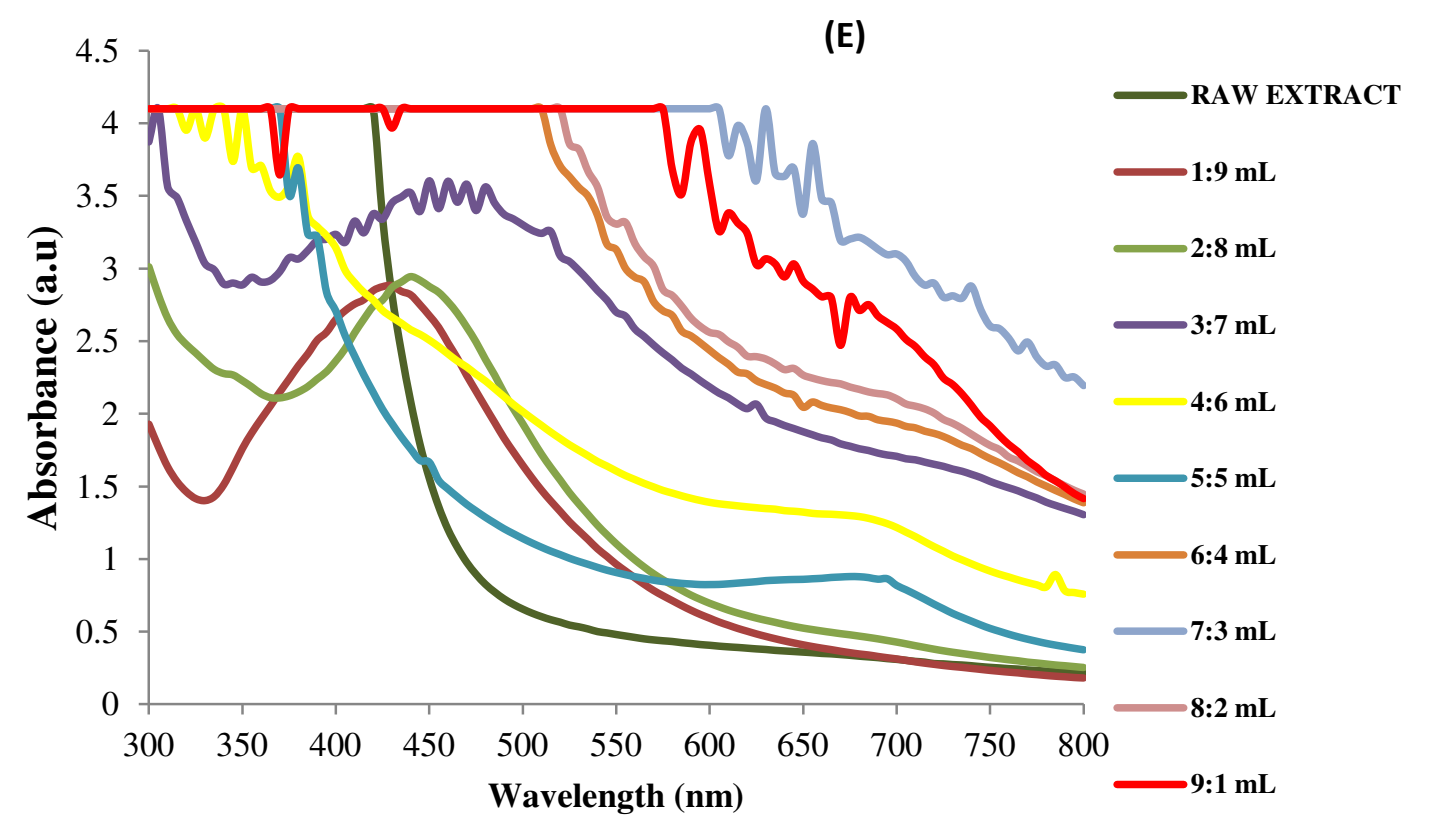

(B)

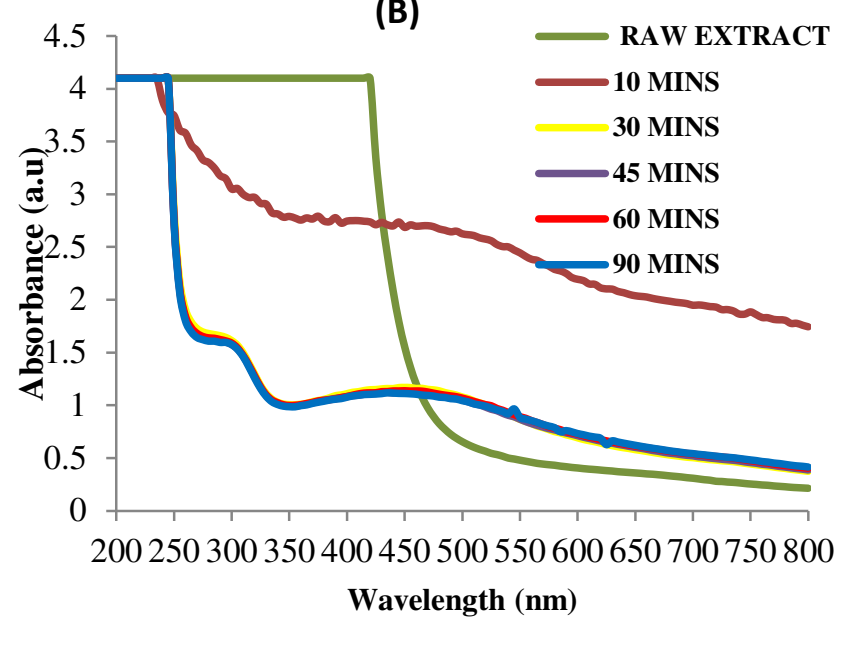

(D)

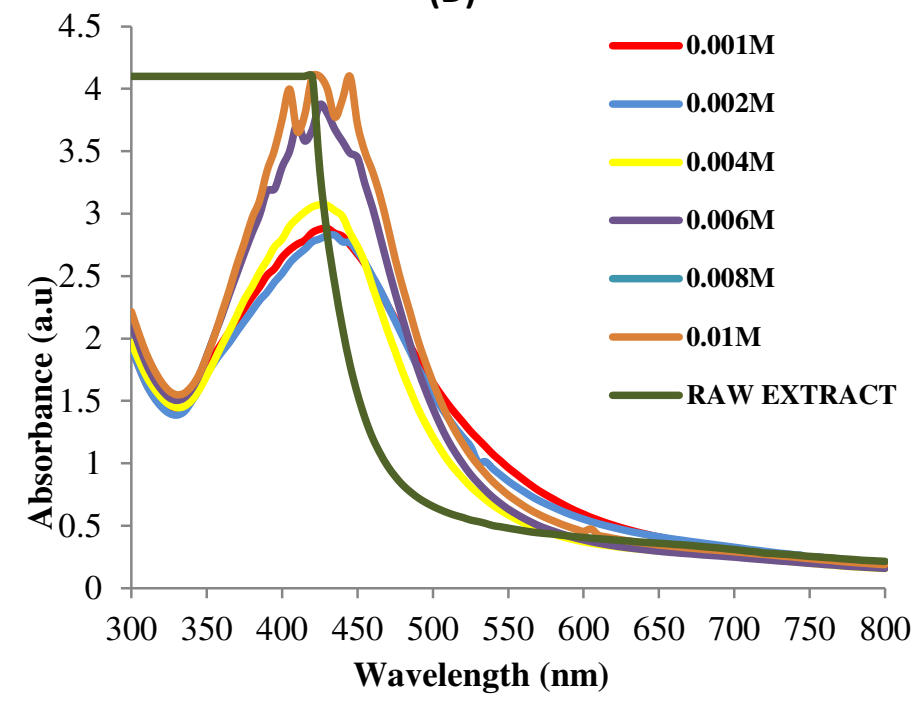


Figure 3

Characterization of TD-AgNPs

(A) UV-Vis Absorption spectrum (B) FTIR Spectrum, (C) SEM Image, (D) EDX spectrum (E) TEM image and (F) XRD pattern of TD-AgNPs
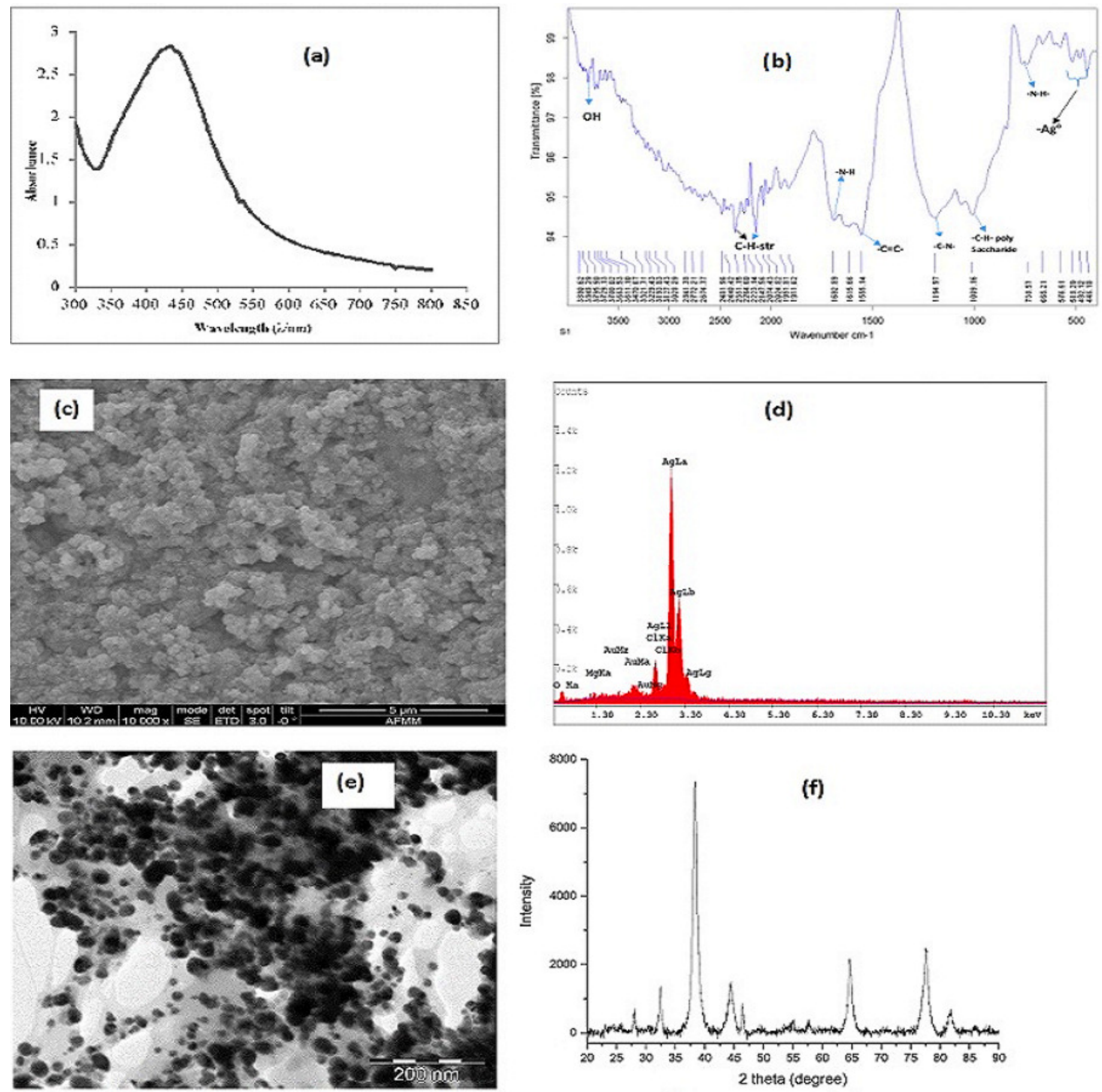


\section{Figure 4}

Antimicrobial activity of synthesized silver nanoparticles (TD-AgNPs)

Antimicrobial activity of synthesized silver nanoparticles (TD-AgNPs), TD Extract, Positive Control and Negative Control against Escherichia coli, Salmonella typhirium, Salmonella enterica and Bacillus

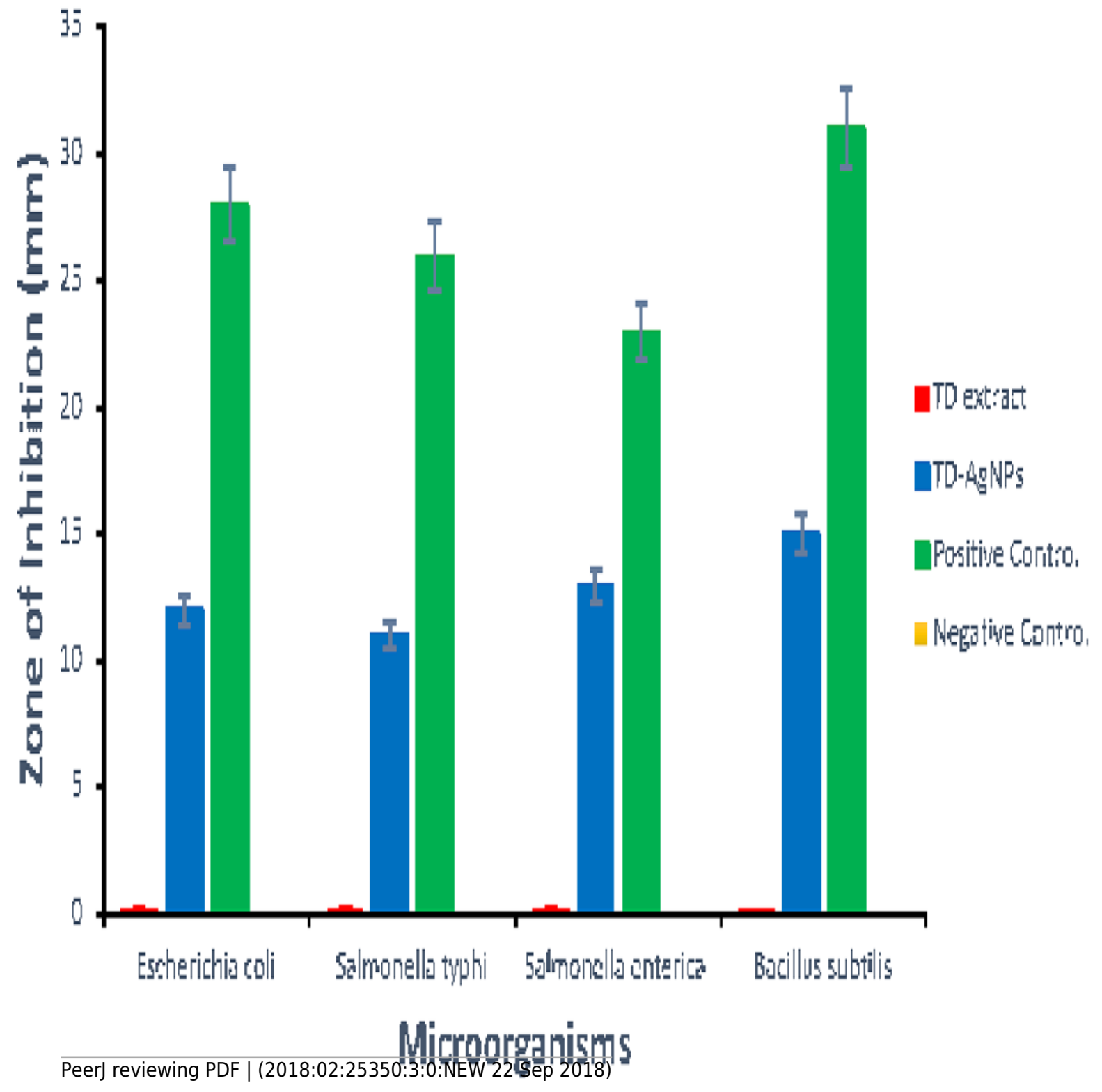


Table $\mathbf{1}$ (on next page)

Phytochemical screening test result on $T$. diversifolia 
2

3 Table 1:

4 Phytochemical screening test results on $T$. diversifolia

\begin{tabular}{|l|l|c|}
\hline $\mathbf{S} / \mathbf{N}$ & Phytochemical screening test done & Tithonia diversifolia leaf extract \\
\hline $\mathbf{1 .}$ & Test for phenol (FeCl ${ }_{3}$ test) & - \\
\hline $\mathbf{2 .}$ & Test for Saponins (Froth's test) & + \\
\hline $\mathbf{3 .}$ & Test for triterpenes & + \\
\hline $\mathbf{4 .}$ & Test for Flavonoids & + \\
& (a) Alkali's test & + \\
\hline $\mathbf{5 .}$ & Test for Alkaloids & - \\
& (a) Mayer's test & + \\
\hline $\mathbf{6 .}$ & Test for steroids (Salkowski's test) & - \\
\hline $\mathbf{7 .}$ & Test for sterols (Libermann-Buchard) & + \\
\hline
\end{tabular}

5 Table key: $\quad+=$ Present,

$6 \quad-=$ Absent 